\title{
The Primary Structure of Alamethicin
}

\author{
By J. W. PAYNE, R. JAKES AND B. S. HARTLEY \\ Microbiological Research Establishment, Porton Down, Wilts., U.K., and Medical Research Council Labora- \\ tory of Molecular Biology, Hills Road, Cambridge CB2 2QH, U.K.
}

(Received 16 January 1970)

\begin{abstract}
Alamethicin, an antibiotic that can transport cations and induce action potentials in synthetic membranes, is shown to be a cyclic peptide with 18 residues including 7 - $\alpha$-aminoisobutyric acid residues, two glutamine residues and one free carboxyl group. The composition indicates microheterogeneity. Alamethicin itself and many peptides derived from it are immune to enzymic digestion, but specific partial acid cleavages have allowed determination of the complete sequence. Diborane reduction has shown that the $\alpha$-carboxyl group of glutamine-18 is free, but the ring is formed by a peptide bond between the imino group of proline- 1 and the $\gamma$-carboxyl group of glutamic acid-17. The structure is contrasted with that of other cation-transporting antibiotics. Model building allows a structure that could stack to form a tunnel with a lipophilic exterior and hydrophilic interior and flexible internal arms formed by the pendant $C$-terminal glutamine residue.
\end{abstract}

Alamethicin (antibiotic $U$ 22324) is an extracellular peptide from Trichoderma viride (Meyer \& Reusser, 1967). In common with many peptide antibiotics, and cell-wall peptides from microorganisms, it is synthesized enzymically rather than by ribosomes (Reusser, 1967 ; Bodanszky \& Perlman, 1969). Alamethicin is of especial interest since, in lipid bilayers, it can induce action potentials that are sensitive to changes in the applied voltage or ionic gradient, and to the addition of chemicals such as spermine, polylysine or protamine (Mueller \& Rudin, 1968a,b). This small molecule therefore mimics many of the properties that are presumed for membrane proteins and its mechanism of action may be a useful model for ion-transport in biological membranes. Determination of the structure of alamethicin is a prerequisite to understanding its mechanism, so we have investigated the covalent structure as a step in this direction.

Meyer \& Reusser (1967), by amino acid analysis and elementary analysis of alamethicin concluded that its composition was $\left(\mathrm{Gln}_{2}, \mathrm{Glu}, \mathrm{PrO}_{2}, \mathrm{Gly}\right.$,$\left.\mathrm{Ala}_{2}, \mathrm{Val}_{2}, \mathrm{Leu}, \mathrm{Aib}_{\mathbf{8}}\right)^{*}$ where all optically active amino acids were in the L-configuration. The absence of an $N$-terminal residue persuaded them that the peptide was cyclic. We find that it contains seven and not eight residues of $\alpha$-aminoisobutyric acid, and that the 18 residues are in normal peptide linkage except that the $\gamma$-carboxyl group of glutamic acid-17 is linked to the imino group of proline-1.

* Abbreviation: Aib in amino acid sequences, $\alpha$ aminoisobutyric acid.
The structure thus becomes a ring of 17 residues with a pendant $C$-terminal glutamine residue.

\section{MATERIALS AND METHODS}

Alamethicin was obtained from Dr G. B. Whitfield of the Upjohn Co. (Kalamazoo, Mich., U.S.A.) through Dr A. I. McMullen. The enzymes used were chymotrypsin, pepsin and papain (Worthington Biochemical Corp., Freehold, N.J., U.S.A.), subtilisin B and alkaline bacterial proteinase (Novo Terapeutisk Laboratorium, Copenhagen, Denmark), thermolysin (Daiwa Kasei K. K., Osaka, Japan), Streptomyces peptidase, pronase and Al bacterial proteinase (gifts from Dr F. Sanger), Sorangium lytic proteinases $\alpha$ and $\beta$ (gifts from Dr D. Whitaker, Ottawa, Canada) and porcine elastase (Shotton \& Hartley, 1970).

Amino acid analysis. Samples of alamethicin were hydrolysed with $6 \mathrm{M}-\mathrm{HCl}$ in evacuated sealed tubes at $105^{\circ} \mathrm{C}$ for various times. The resulting amino acids were analysed in an automatic amino acid analyser by the procedure of Spackman (1963). We found it difficult to obtain convincing analyses for $\alpha$-aminoisobutyric acid since the colour yield of this amino acid was found to be very low (about 12\% that of leucine) and the content of this residue in alamethicin is high. Commercial samples of $\alpha$-aminoisobutyric acid may contain impurities that prevent accurate determination of a colour constant, and quantitative transfer of samples to the column of the analyser is another source of error. We therefore synthesized $N$-benzyloxycarbonylglycyl- $\alpha$-aminoisobutyric acid, hydrolysed several samples of this and analysed the hydrolysates as above. Ratios of colour yields for glycine and $\alpha$-aminoisobutyric acid are thus obtained, which are corrected for both hydrolytic and analytical losses. The 
colour yield of $\alpha$-aminoisobutyric acid relative to that of glycine was $13.7 \pm 0.3 \%$ and was found to be essentially independent of hydrolysis time from 20 to $90 \mathrm{~h}$. In this way the ratio of glycine to $\alpha$-aminoisobutyric acid in hydrolysates of alamethicin can be accurately determined.

Benzyloxycarbonylglycyl- $\alpha$-aminoisobutyric acid. $\alpha$ Aminoisobutyric acid $(1.03 \mathrm{~g})$ in $15 \mathrm{ml}$ of $33 \%(v / v)$ dioxan was adjusted to $\mathrm{pH} 10$ with $\mathrm{NaOH}$ and allowed to react for $1 \mathrm{~h}$ at $95^{\circ} \mathrm{C}$ with benzyloxycarbonylglycine $p$ nitrophenyl ester $(1.0 \mathrm{~g})$ in $10 \mathrm{ml}$ of dioxan plus $0.8 \mathrm{ml}$ of triethylamine. Water $(80 \mathrm{ml})$ was added, and the mixture was adjusted to $\mathrm{pH} 2$ with $\mathrm{HCl}$ and extracted three times with $20 \mathrm{ml}$ of ethyl acetate. The organic phase was washed three times with $20 \mathrm{ml}$ of $0.2 \mathrm{M}$-sodium phosphate buffer, $\mathrm{pH} 7$, and once with water to remove $p$-nitrophenol. After removal of the solvent, the oil was crystallized from water, recrystallized twice and dried in vacuo to give $168 \mathrm{mg}$ of fine colourless needles, m.p. $155^{\circ} \mathrm{C}$ (literature m.p. $155^{\circ} \mathrm{C}$; Bergman, Zervas, Fruton, Schneider \& Schleich, 1935).

Attempts to digest alamethicin with proteinases. Samples $(0.5 \mathrm{mg})$ of alamethicin or 'linear alamethicin' (peptide 1 , see below) were incubated in $0.5 \mathrm{ml}$ of buffer with $0.01 \mathrm{mg}$ of chymotrypsin, thermolysin, subtilisin (Novo), papain, pepsin, pronase, elastase, Sorangium $\alpha$ - and $\beta$-lytic proteases, Streptomyces peptidase, and alkaline and $\mathrm{Al}$ bacterial proteinases. Buffers were $50 \mathrm{~mm}-\mathrm{NH}_{4} \mathrm{HCO}_{3}$ for all except pepsin [5\% (v/v) formic acid] and papain (50 mM-mercaptoethanol-0.1 M-pyridine acetate, pH6.5). A parallel series of digests were set up in buffers that contained $10 \%(v / v)$ ethanol in the hope that this might disaggregate the substrate (Chapman et al. 1969). Controls containing $0.5 \mathrm{mg}$ of the B-chain of oxidized insulin (a gift from Dr F. Sanger) were digested in parallel to confirm that the enzymes were active under the experimental conditions, and further controls in which substrate was omitted allowed for any autolysis of the enzymes themselves. Incubations were for $13 \mathrm{~h}$ at $37^{\circ} \mathrm{C}$, but for $13 \mathrm{~h}$ at $60^{\circ} \mathrm{C}$ with thermolysin. About half of each digest was subjected to high-voltage paper electrophoresis at $\mathrm{pH} 2$ in a flat plate apparatus (to avoid possible extraction of substrate or products into the organic coolant of the Michl tanks). Samples were also taken for $N$-terminal analysis by the 'dansyl' procedure (see below).

Partial acid hydrolysis. Because alamethicin was found to be insoluble in dilute acid, $12 \mathrm{M}-\mathrm{HCl}$ was used for all partial hydrolyses. Preliminary experiments for various times at $60^{\circ} \mathrm{C}$, followed by freeze-drying and paper electrophoresis at $\mathrm{pH} 2$, revealed a rapid initial liberation of peptides that stained yellow with cadmium-ninhydrin reagent (Heilmann, Barrolier \& Watzke, 1957) and blue with isatin (Smith, 1953), indicating $N$-terminal proline. Subsequently an incubation for $30 \mathrm{~min}$ at $37^{\circ} \mathrm{C}$ in $12 \mathrm{M}$ $\mathrm{HCl}$ was adopted as the optimum condition for selective cleavage of alamethicin.

Sequence methods. The 'dansyl' technique (Gray \& Hartley, 1963; Gray, 1967a) was used for $N$-terminal analysis, with chromatography on thin layers of polyamide (Tang \& Hartley, 1970) to identify DNS-amino acids. DNS- $\alpha$-aminoisobutyric acid ran as a spot slightly ahead of DNS- $\mathrm{NH}_{2}$ after two-dimensional chromatography [solvent 1: formic acid-water $(3: 197, \nabla / v)$; solvent 2: benzene-acetic acid $(9: 1, \nabla / v)]$ and between
DNS-alanine and DNS- $\mathrm{NH}_{2}$ after rerunning in solvent 3 [ethyl acetate-methanol-acetic acid (20:1:1, by vol.)] of the above system. The 'dansyl'-Edman procedure (Gray, 1967b) was used for sequential degradation. Low yields of DNS- $\alpha$-aminoisobutyric acid and occasional incomplete cleavage of $N$-terminal $\alpha$-aminoisobutyric acid were frequently observed during the degradation. The low yields are not due to destruction of DNS- $\alpha$ aminoisobutyric acid during acid hydrolysis and may be due to incomplete reaction with DNS chloride because of steric hindrance by the two $\alpha$-methyl groups. Steric hindrance, either in reaction with phenyl isothiocyanate, or in cyclization of phenylthiocarbamoyl- $\alpha$-aminoisobutyric acid may also explain the incomplete removal of $N$-terminal $\alpha$-aminoisobutyric acid.

Amide analysis. Duplicate samples $(2-4 \mathrm{mg})$ of alamethicin were hydrolysed with $1 \mathrm{M}-\mathrm{H}_{2} \mathrm{SO}_{4}$ for various times from $2-24 h$ in a boiling-water bath. Liberated ammonia was determined by use of Nessler's reagent (King, 1951).

Reaction with diborane. The procedure used was essentially that described by Atassi \& Rosenthal (1969). Samples of alamethicin ( $4 \mathrm{mg}$ ) were converted to the trifluoroacetates and treated at $-10^{\circ} \mathrm{C}$ for $2 \mathrm{~h}$ with several different concentrations of diborane in tetrahydrofuran $(0.5 \mathrm{ml})$. After reduction, samples were dried, treated with methanol ( $1 \mathrm{ml})$ and trifluoroacetic acid (2 drops) at room temperature for $2 \mathrm{~h}$ and freeze-dried. They were again treated with methanol $(2 \mathrm{ml})$ and, after final drying, samples were removed for acid hydrolysis. The reduction of glutamine and glutamyltyrosine was carried out similarly (see the Results section).

\section{RESULTS}

\section{Production and purification of peptides}

Enzymic digests. All attempts to cleave alamethicin or peptide 1 (see below) with peptidases or proteinases were uniformly unsuccessful, although extensive degradation of the B-chain of oxidized insulin was observed in parallel control digests. No new bands could be detected by cadmium-ninhydrin reagent or by chlorine-tolidine reaction after paper electrophoresis of the digests, and there was no appreciable diminution of the band of substrate itself. No end groups were detected by the 'dansyl' method in digests of alamethicin, and only DNS-proline was found in digests of peptide 1. This almost unique resistance to proteolysis is perhaps not unexpected for the cyclic, highly constrained, structure of alamethicin itself, but is surprising for the open chain form of alamethicin (peptide 1). The explanation may reside in the high content and fairly uniform distribution of $\alpha$-aminoisobutyric acid, which with its two $\alpha$ methyl groups will place severe steric constraints on the folding of the peptide at the active centre of the enzyme. For example, in the sequence -Leu-Aibit is not possible to fit the leucine residue to the conformation of the substrate at the catalytic site 


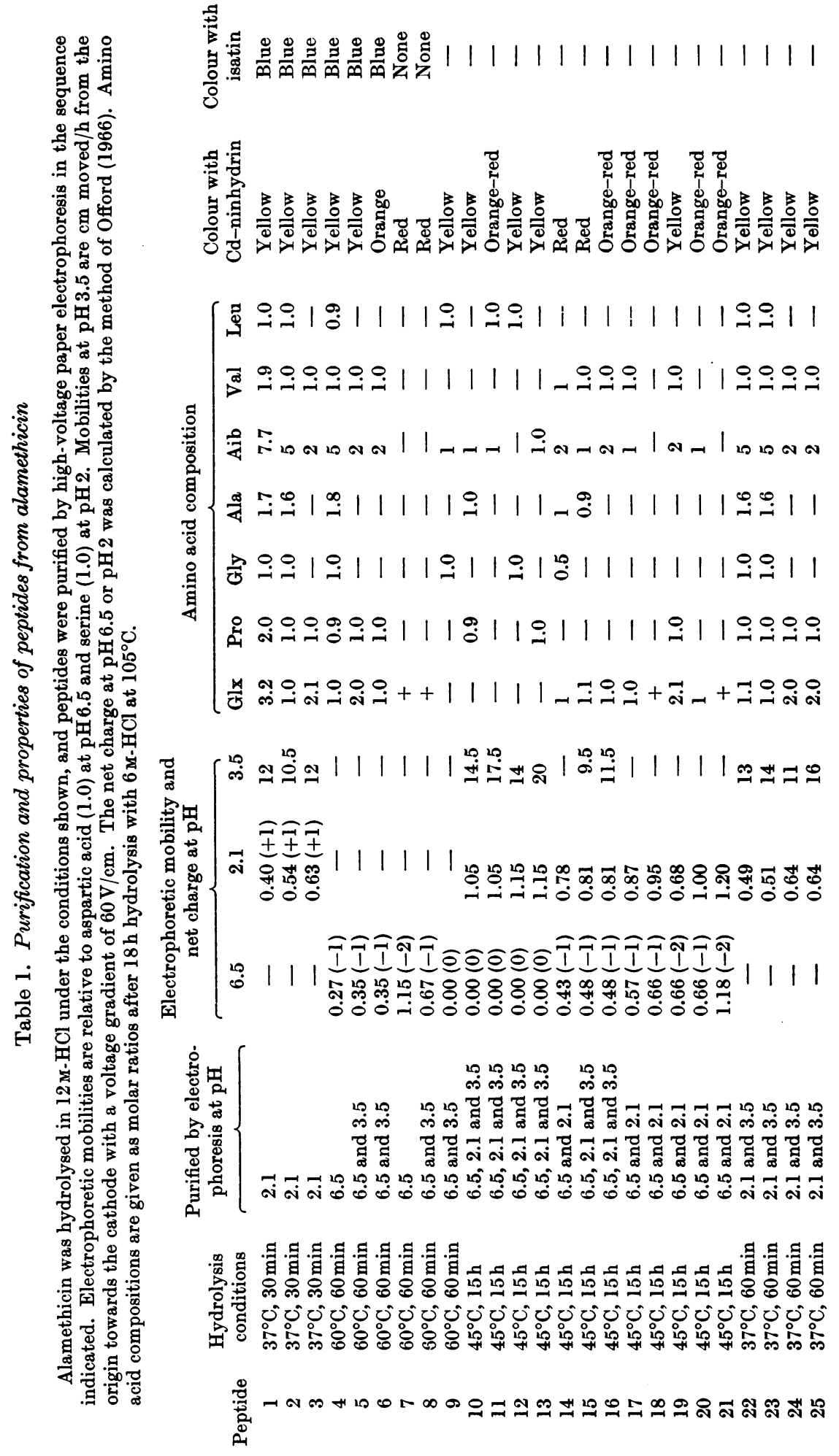


of $\alpha$-chymotrypsin (Blow, 1969), since one of the $\alpha$-methyl groups or the $\alpha$-carbonyl group of $\alpha$ aminoisobutyric acid must overlap the position of histidine-57 in the chymotrypsin model. We suggest that such peptides containing $\alpha$-aminoisobutyric acid might be of interest in studies like those of Schecter \& Berger (1966) on the specificity of proteolytic enzymes.

Partial acid hydrolysis. Mild acid hydrolysis with $12 \mathrm{~m}$-hydrochloric acid for $30 \mathrm{~min}$ at $37^{\circ} \mathrm{C}$ did, however, produce specific cleavage of alamethicin. Only $N$-terminal proline was revealed by 'dansylation' of a sample of the digest, so the only bonds to be split are those involving the imino group of this residue. The absence of DNS- $\alpha$-aminoisobutyric acid from this digest indicates that free $\alpha$-aminoisobutyric acid was not liberated during the hydrolysis; this fact, together with the analyses for peptides 2 and 3 (see below), provides additional evidence for the presence of only seven $\alpha$-aminoisobutyric acid residues in alamethicin. When the above digest was fractionated by electrophoresis at pH 2, only three peptide bands were observed: peptides 1, 2 and 3 (Table 1). Each stained yellow with cadmium-ninhydrin reagent and blue with isatin, indicating $N$-terminal proline, and each appeared to be a single component on further electrophoresis at pH 3.5. Reaction with chlorinetolidine reagent revealed an additional intense band at the origin, which is presumably unhydrolysed aggregated alamethicin (Chapman et al. 1969).

Amino acid analyses (Table 1) showed that peptide 1 had a composition identical with that of alamethicin itself, and peptides 2 and 3 had compositions that together account for the 18 amino acid residues. 'Dansylation' confirmed that each had $N$-terminal proline. Hence the mild acid hydrolysis splits selectively on the $N$-terminal side of the two proline residues.

More severe acid hydrolysis (12 M-hydrochloric acid for $60 \mathrm{~min}$ at $60^{\circ} \mathrm{C}$ ) produced some smaller acidic peptides, which were separated by electrophoresis at pH 6.5 and further purified by electrophoresis at pH 3.5 (peptides 4-9; Table 1). Peptides 4 and 5 are clearly similar to peptides 2 and 3 , and peptides 7 and 8 must be fragments of peptide 3 . Peptide 9 was purified as one of the most anionic components from electrophoresis at pH3.5 of the neutral band from the pH 6.5 electrophoresis.

Still smaller fragments were obtained from a partial hydrolysis with $12 \mathrm{M}$-hydrochloric acid for $15 \mathrm{~h}$ at $45^{\circ} \mathrm{C}$. The purification and properties of these peptides (10-21) are summarized in Table 1. Also listed in this table are the properties of peptides similar to peptides 2 and 3 that were isolated from another mild acid hydrolysate of alamethicin. Peptides 22 and 23 demonstrate that peptide 2 can presumably exist in different forms separable

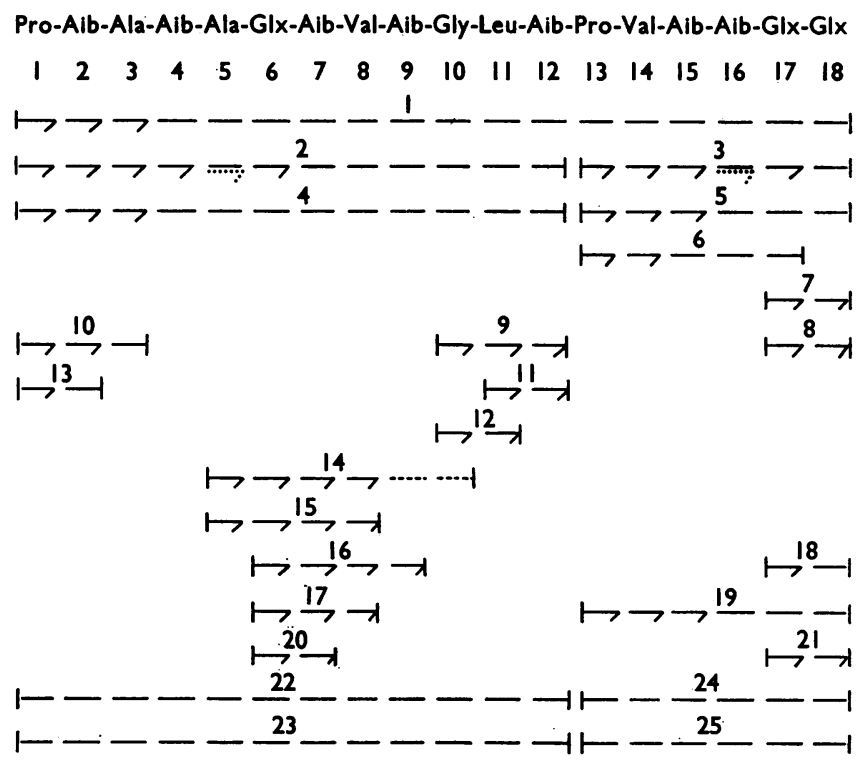

Fig. 1. Sequence of peptides obtained from partial hydrolysates of alamethicin. The symbols $|--|$ indicate the quantitative composition of a peptide, whereas qualitative analyses are indicated thus $|\cdots \ldots \ldots|$. Sequential 'dansyl'-Edman analysis is indicated $\mapsto \neg$, but equivocal steps are indicated $\%$. The peptides are numbered as in Table 1. 
by electrophoresis at $\mathrm{pH} 3.5$, and peptides 24 and 25 are similarly two varieties of peptide 3 . It is probable that these variations arise from the presence of amide groups, and that both peptides 2 and 3 are likely to contain at least one amide group.

\section{Amino acid sequence of the peptides}

Fig. 1 summarizes the sequence studies on these peptides. The incomplete cleavage of $N$-terminal $\alpha$-aminoisobutyric acid and the low yield of DNS$\alpha$-aminoisobutyric acid produced some problems of interpretation in the 'dansyl'-Edman analysis. For instance, traces of DNS- $\alpha$-aminoisobutyric acid were found in step 3 of peptide 1 , though DNS-alanine was clearly the major product. We are not therefore able to exclude a minor variety of peptide 1 with $N$-terminal sequence Pro-Aib-Aib-. A similar ambiguity applies to step 5 in the sequence of peptide 2, though the appearance of DNSglutamic acid at step 6 allows us to define this position. Analogous difficulties were encountered after residue 3 of peptide 3 , although a trace of DNS-glutamic acid was unambiguously detected after four cycles of 'dansyl'-Edman treatment. Because of these difficulties, it proved impractical to try to sequence completely peptides 2 and 3 directly and we therefore attempted to obtain enzymically cleaved fragments. However, all attempts to digest peptide 2 or peptide 3 with proteinases were unsuccessful, except for a thermolysin digest of peptide 2. Incubating peptide 2 with thermolysin (substrate/enzyme ratio 50:1) at $60^{\circ} \mathrm{C}$ for $4 \mathrm{~h}$ at $\mathrm{pH} 8$ gave only one small peptide on electrophoresis at $\mathrm{pH} 2(\mathrm{~m} 1.10$ relative to that of serine) which stained red with cadmiumninhydrin reagent. Amino acid analysis and sequence studies showed it to be leucyl- $\alpha$-aminoisobutyric acid, consistent with its electrophoretic mobility. Since no other fragments were liberated, this must be the $C$-terminal sequence of peptide 2 . It is noteworthy that the bond between glycine-10 and leucine 11 was split readily by thermolysin in peptide 2 but not in peptide 1 (Matsubara, Singer and Sasaki, 1969).

The $C$-terminus of peptides 1 and 3 presented more of a problem. No amino acids were liberated by carboxypeptidase $A$ and hydrazinolysis yielded no free amino acid. However, comparison of the compositions and partial sequences of peptides 5 and 6 shows that -Glx must be $C$-terminal in the former, and the compositions, sequences and electrophoretic mobilities of peptides 7 and 8 show that peptide 5 must have $C$-terminal -Glx-Glx. The very mild acid hydrolysis that gave rise to peptides 1, 2 and 3 produced no end groups except proline-1 and proline-13, so peptides 1,2 and 3 must be the sole products. Peptide 2 is clearly $N$-terminal in peptide 1 and therefore peptide 3 is $C$-terminal. The compositions and sequences of all these partial hydrolysis products therefore allow us to write the sequence for peptide 1 as :

$$
\begin{aligned}
& \text { Pro-Aib-Ala-Aib-Ala-Glx-Aib-Val-Aib- } \\
& \begin{array}{lllllllll}
1 & 2 & 3 & 4 & 5 & 6 & 7 & 8 & 9
\end{array} \\
& \text { Gly-Leu-Aib-Pro-Val-Aib-Aib-Glx-Glx }
\end{aligned}
$$

\section{Amino acid composition of alamethicin}

Table 2 shows the amino acid analyses of alamethicin hydrolysed for various times. Whereas most of the amino acids are present in integral quantities, alanine $(1.64 \pm 0.05 \mathrm{~mol} / \mathrm{mol})$ and $\alpha$ aminoisobutyric acid $(7.5 \pm 0.14 \mathrm{~mol} / \mathrm{mol})$ vary significantly from integral values. Non-integral values for alanine and $\alpha$-aminoisobutyric acid were also found in the analyses of peptides 1 and 2. Although during the acid hydrolysis of polypeptides several factors can lead to low values with certain amino acids, e.g. serine and threonine are significantly destroyed, and valine, isoleucine and leucine may only be slowly released, no such considerations normally apply to alanine. Great care was taken to obtain an accurate colour constant for $\alpha$-aminoisobutyric acid (see the Materials and Methods section), and so its non-integral value is considered to be real and significant. The interrelated variation from integral values for these two amino acids, together with the fact that only seven $\alpha$-aminoisobutyric acid residues could be located by the sequence studies discussed above, leads us to conclude that our sample of alamethicin is probably a mixture of two or more forms. The predominant form contains two alanine and seven $\alpha$-aminoisobutyric acid residues, whereas in the remaining molecules an alanine residue at position-3 or position-5 is replaced by an $\alpha$-aminoisobutyric acid residue.

\section{Table 2. Amino acid composition of alamethicin}

Samples were hydrolysed with $6 \mathrm{M}-\mathrm{HCl}$ in sealed tubes at $105^{\circ} \mathrm{C}$ for the periods indicated. Molar ratios are expressed relative to leucine (1.00). Results are the average of from two to five separate hydrolyses.

$\begin{array}{lllll} & 20 \mathrm{~h} & 44 \mathrm{~h} & 62 \mathrm{~h} & 90 \mathrm{~h} \\ \text { Glu } & 3.03 & 3.03 & 3.05 & 3.04 \\ \text { Pro } & 1.98 & 1.95 & 1.87 & 2.10 \\ \text { Gly } & 1.02 & 1.04 & 1.00 & 1.02 \\ \text { Ala } & 1.62 & 1.62 & 1.67 & 1.64 \\ \text { Aib } & 7.42 & 7.52 & 7.62 & 7.36 \\ \text { Val } & 1.83 & 1.84 & 1.89 & 1.90 \\ \text { Leu } & 1.00 & 1.00 & 1.00 & 1.00\end{array}$




\section{Amide groups and the ring structure of alamethicin}

Amide analyses by the Nessler procedure (King, 1951) showed that our sample of alamethicin contained $2.0 \pm 0.08$ amide groups/molecule, confirming the analyses of Meyer \& Reusser (1967). A single acid group with an apparent $\mathrm{p} K_{a} 5.8$ was indicated by $\mathrm{pH}$-titration studies of alamethicin, whereas Meyer \& Reusser (1967) found a single group of $\mathrm{p} K_{a}$ 5.5. Like them, we found no free amino group by titration, by ninhydrin reaction or by 'dansylation'. These results suggest, but do not prove, that alamethicin is a cyclic peptide with two glutamine residues. However, because alamethicin is not synthesized on ribosomes by the usual protein-synthesizing machinery (Reusser, 1967), the possibility of unusual peptide bonds such as $\gamma$-glutamyl bonds must be taken into account.

The electrophoretic mobilities at $\mathrm{pH6.5}$ of peptides 7 and 21 suggest that they are both Glu-Glu, whereas peptides 8 and 18 must be GluGln or Gln-Glu. Samples of peptides 18 and 21 were therefore 'dansylated', and another portion of each was submitted to one cycle of Edman degradation and then 'dansylated'. The mobilities of DNS-peptides 18 and 21 are shown in Fig. 2 and clearly support the proposed charge structure. After one cycle of Edman degradation followed by 'dansylation', the product from peptide 18 was indistinguishable from DNS-glutamine by two-

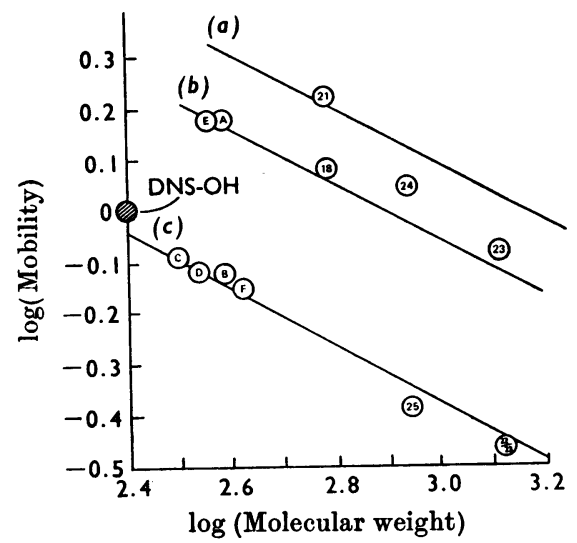

Fig. 2. Electrophoretic mobilities of DNS-amino acids and DNS-peptides at pH6.5. Mobilities were measured from the position of DNS- $\mathrm{NH}_{2}$ and are expressed relative to that of DNS-OH (Gray, 1967b). Molecular weights for peptides 18 and 21-25 were calculated from the amino acid compositions given in Table 1 . The following standard compounds were also run: A, DNS-glutamic acid; B, DNS-glutamine; C, DNS-alanine; D, DNSvaline; E, DNS-aspartic acid; F, DNS-glycyl-leucine. (a) $\mathrm{e}=-3 ;(b) \mathrm{e}=-2 ;$ (c) $\mathrm{e}=-1$. dimensional t.l.c. or by flat-plate paper electrophoresis at $\mathrm{pH} 4.0$ or 6.5. The product from peptide 21 was indistinguishable from DNS-glutamic acid in the same separation systems. Susceptibility to the Edman degradation may be taken as evidence for an $\alpha$-peptide bond, so peptide 21 is $\alpha$-glutamylglutamic acid and peptide 18 is $\alpha$-glutamylglutamine or $\alpha$-glutamylisoglutamine. The latter possibility was eliminated by applying the product from the one step Edman degradation of peptide 18 to the amino acid analyser calibrated with glutamine and isoglutamine. A peak appeared in the position of glutamine (between threonine and serine) but nothing appeared in the position of isoglutamine (approximately the position of tyrosine).

To establish the position of the second amide group further samples of peptides 2 and 3 were obtained by hydrolysis of alamethicin with $12 \mathrm{M}$ hydrochloric acid for $60 \mathrm{~min}$ at $37^{\circ} \mathrm{C}$. Bands corresponding to peptides 1,2 and 3 were observed and were purified further at $\mathrm{pH} 3.5$, giving peptides 22-25 (Table 1). Their electrophoretic mobilities are shown in Table 1, and those of the corresponding DNS-peptides are shown in Fig. 2. By using the procedures of Offord (1966) and Gray (1967b), we conclude that peptides 22 and 25 have no net acidic groups, whereas peptide 24 has a single net acidic group at $\mathrm{pH}$ 6.5. Peptide 23 appeared to be a mixture of a neutral and a singly charged species. Amide analysis of peptide 22 showed $1 \mathrm{~mol}$ of amide nitrogen/mol of peptide, so it seems reasonable to conclude that the residue at position 6 is glutamine, and that one component of peptide 23 is the deamidated variety with glutamic acid-6. Glutamine-6 must be linked to $\alpha$-aminoisobutyric acid- 7 by an $\alpha$-peptide bond, since it readily underwent Edman degradation in peptides 15, 16, 17 and 20 (Fig. 1). Peptide 24 could be Pro-ValAib-Aib-Glu-Gln, but the expected species Pro-ValAib-Aib-Glu-Glu was not detected, and we cannot readily explain why peptide 25 was neutral. Perhaps the acid-lability of the $\gamma$-bond between glutamic acid-17 and proline-1 is enhanced by the intermediate formation of a relatively stable cyclic imide as in Scheme 1.

\section{Diborane reduction of alamethicin}

With the linear amino acid sequence established, and the positions of the two glutamine residues confirmed, it remained to identify the presumed linkage that renders alamethicin cyclic. The two possibilities were a link between the imine nitrogen atom of proline-1 and either the $\alpha$-carboxyl group of glutamine-18 or the $\gamma$-carboxyl group of glutamic acid-17. Thus to distinguish between these two possibilities we sought to establish whether a free 


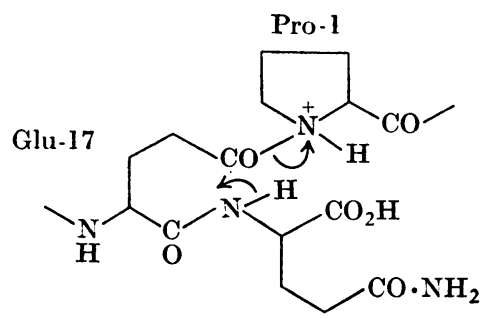

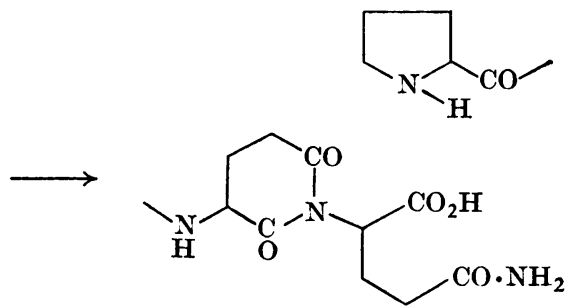

Gln-18

Scheme 1. Possible ring cleavage mechanism.<smiles>N[C@H](CCCO)C(=O)O</smiles>

(I)<smiles>NC(CO)CCC(=O)O</smiles>

(II)<smiles>NC1CCCOC1</smiles>

(III)<smiles>NC1CCOOC1</smiles>

(IV)<smiles>NCCCCO</smiles>

(V)

Scheme 2. Possible products of diborane reduction and acid hydrolysis of glutamic acid and glutamine residues.

$\gamma$ - or $\alpha$-carboxyl group is present in alamethicin by reducing the carboxyl group to the primary alcohol and oxidizing the product with periodate (Chibnall $\&$ Rees, 1958). If the $\gamma$-carboxyl group of glutamic acid-17 were free the product obtained on reduction and hydrolysis would be $\alpha$-amino- $\delta$-hydroxyvaleric acid (I, Scheme 2), whereas a free $\alpha$-carboxyl group in glutamine-18 would yield $\gamma$-amino- $\delta$ hydroxyvaleric acid (II, Scheme 2). Only the latter would yield formaldehyde after periodate oxidation, which can be readily determined by the method of Rees (1958).

Atassi \& Rosenthal (1969) suggest the use of diborane for the direct and specific reduction of carboxyl groups in peptides to alcohols, so we investigated the reaction of this reagent with alamethicin. Table 3 shows the results of several experiments in which the products of reduction and acid hydrolysis were applied to the amino acid analyser. Many ninhydrin-positive products are formed, which interfere with the interpretation of the analysis. Electrophoresis at $\mathrm{pH} 2$ of the reaction mixtures from experiment 1 showed many products. Some, which migrate faster than lysine, must have several positive charges. Similar highly charged species were observed when a sample of glutamine was reduced under the conditions of experiment 1. Reaction with $0.2 \mathrm{M}$-diborane in tetrahydrofuran for $2 \mathrm{~h}$ at $-10^{\circ} \mathrm{C}$ (experiment 3) did, however, appear to give specific products, the main one being a spot that stained blue with collidine-ninhydrin reagent and migrated slightly faster than lysine at $\mathrm{pH} 2$. A minor product migrated slightly faster than alanine and stained grey. The main product was identical in both colour and mobility with that obtained by a parallel reduction and hydrolysis of free glutamine. In contrast, the reduction of the dipeptide glutaminyltyrosine gave a product corresponding to the $\beta$-amino alcohol derived from tyrosine and also a spot with a mobility equal to that of lysine that stained grey with collidine-ninhydrin. Electrophoresis at $\mathrm{pH} 3.5$ also showed that the major product from reduced alamethicin was identical with that from reduced glutamine, but differed from that from reduced glutaminyltyrosine. The electrophoretic mobilities of the former were consistent with any of structures (III), (IV) or (V) (Scheme 2), but after incubation with alkali under the conditions necessary to open the lactone rings of structures (III) and (IV) the electrophoretic mobilities were unchanged. We therefore believe 
that the major product of mild diborane reduction of alamethicin or of glutamine, followed by hydrolysis, is probably the 2-aminopentane-1,5-diol (V, Scheme 2). Glutamine peptides yield a product that is possibly the $\alpha$-amino- $\delta$-valerolactone (III, Scheme 2).

Periodate oxidation should unambiguously identify the reduction product of an $\alpha$-carboxyl group of an $\alpha$-amino acid. Samples from the hydrolysis of reduced alamethicin (Table 3, experi-

Table 3. Amino acid compositions of samples of alamethicin reduced with diborane under different conditions

Molar ratios are expressed relative to leucine (1.00). In experiment 1 alamethicin $(4.5 \mathrm{mg}$ ) was reduced with $0.5 \mathrm{ml}$ of approx. $1 \mathrm{~m}$-diborane in tetrahydrofuran at $0^{\circ} \mathrm{C}$ for $4 \mathrm{~h}$. In experiments 2,3 and 4 alamethicin $(4.5 \mathrm{mg})$ was reduced at $-10^{\circ} \mathrm{C}$ for $2 \mathrm{~h}$ with $0.5 \mathrm{ml}$ of $1 \mathrm{M}-, 0.2 \mathrm{M}$ - and $0.02 \mathrm{~m}$-diborane in tetrahydrofuran respectively. Experiment 5 was a repeat of experiment 3 on a scale eleven times larger.

$\begin{array}{ccccccc}\text { Expt. no. } & \ldots & 1 & 2 & 3 & 4 & 5 \\ \text { Glu } & & 1.57 & 1.67 & 1.82 & 2.93 & 2.04 \\ \text { Pro } & & 5.82 & 4.12 & 2.10 & 1.94 & 2.10 \\ \text { Gly } & & 0.91 & 1.02 & 1.00 & 1.01 & 1.02 \\ \text { Ala } & 5.90 & 3.84 & 1.87 & 1.61 & 1.61 \\ \text { Aib } & 24.1 & 20.5 & 10.3 & 9.00 & 8.64 \\ \text { Val } & 6.60 & 4.12 & 2.16 & 1.94 & 2.08 \\ \text { Leu } & 1.00 & 1.00 & 1.00 & 1.00 & 1.00\end{array}$

ment 5) and of reduced glutamine were examined by the procedure of Rees (1958). In both cases formaldehyde was obtained, and in the case of reduced alamethicin the yield was $0.35 \mathrm{~mol} / \mathrm{mol}$ of alamethicin. Better yields could probably be obtained by more careful control of the reaction conditions. To check that the $\alpha$-carboxyl group is present in the native structure, and is not an artifact of the reduction procedure, a sample of reduced alamethicin was 'dansylated'. No new $N$-terminal groups were found, so it is clear that the cyclic peptide contains a free $\alpha$-carboxyl group, which must be that of glutamine-18. Hence glutamic acid-1 7 is linked to proline-1 through its $\gamma$-carboxyl group, giving the structure shown in Fig. 3.

\section{DISCUSSION}

Although we have not directly demonstrated the glutamic acid-1 $7^{\gamma}$-proline-1 link, its presence is inferred on the following grounds: (a) Alamethicin contains no amino group, one free carboxyl group and two amide residues/molecule; (b) all the peptide bonds in peptide 1 are $\alpha$-linkages, since the residues can be removed by Edman degradation; (c) amide residues are on glutamine-6 and glutamine18; (d) the molecule has a free $\alpha$-carboxyl group. The high acid-lability of the glutamic acid-1 $7^{\gamma}$ proline-1 bond may be explained by a mechanism

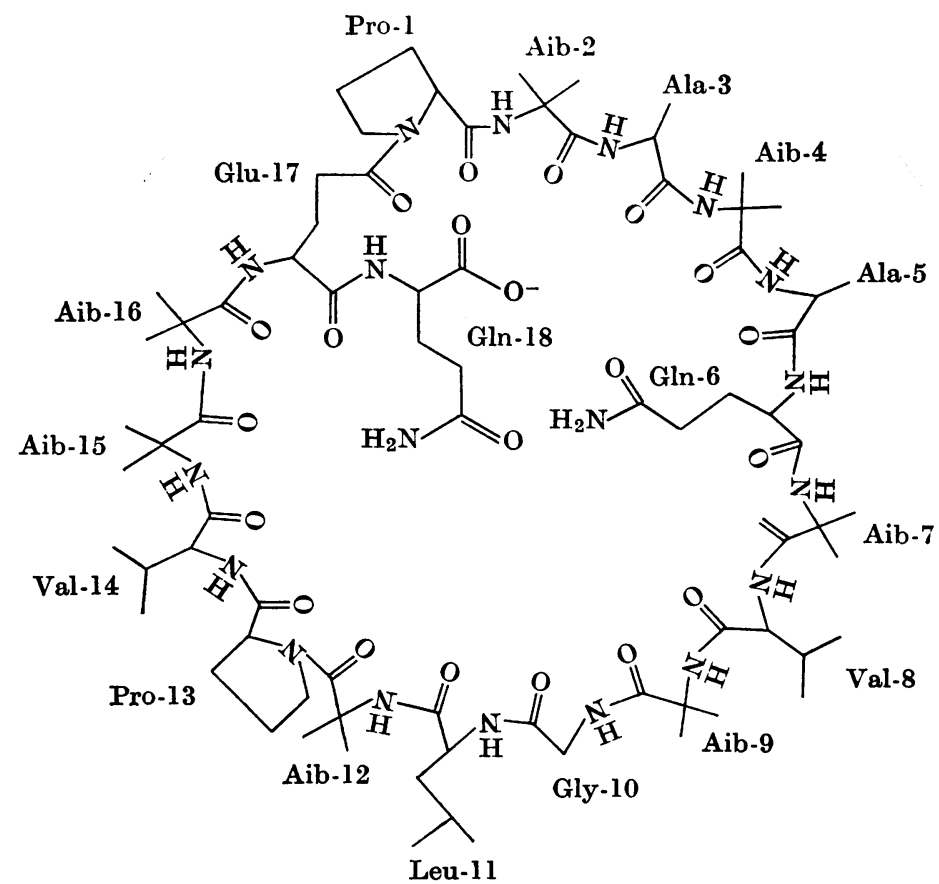

Fig. 3. Diagrammatic structure of alamethicin. 

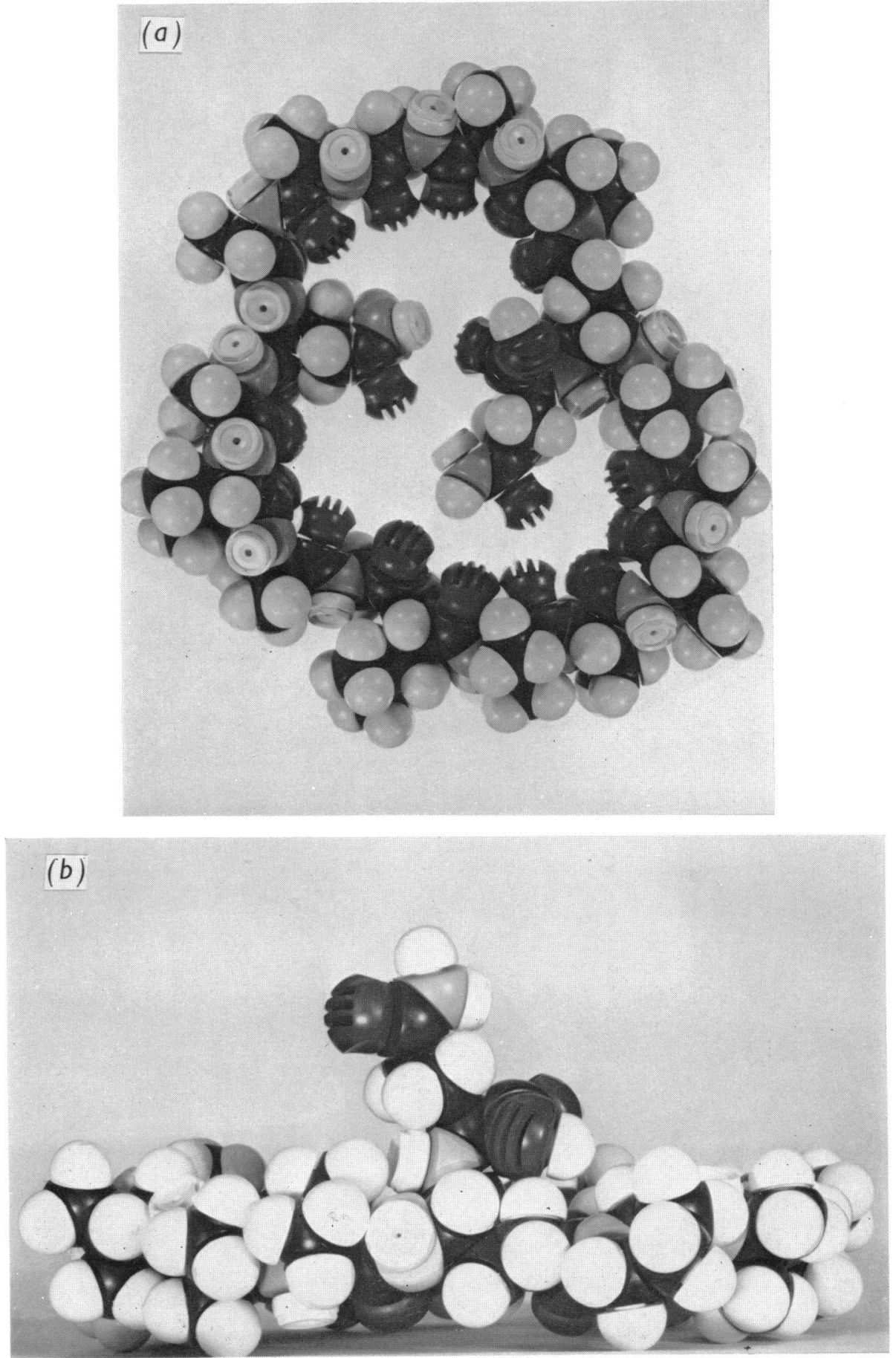

EXPLANATION OF PLATE 1

Space-filling (Corey-Pauling-Koltun) models of alamethicin, illustrating the flexibility of glutamine-18 and its ability to both bridge the ring $(a)$ and extend out from it $(b)$. 
such as that shown in Scheme 1. We have also observed specific cleavage of this bond when alamethicin is incubated for a few hours at $105^{\circ} \mathrm{C}$ in 3 M-ammonia.

Compounds that possess the property of transporting cations across membranes appear, so far, to possess certain common structural features (Kilbourn, Dunitz, Pioda \& Simon, 1967; Dobler, Dunitz \& Krajewski, 1969). They are covalently linked cyclic structures with lipophilic external surfaces (or occasionally linear structures that can take up such conformations), which sequester dehydrated cations. The valinomycin group (macrotetralides, enniatins, gramicidins and valinomycin) are positively charged, whereas the nigericin group (nigericin, monensin) are neutral. Their mode of action is presumed to be either that of simple carriers that confer lipid solubility on the ions transported, or a 'channel mechanism' whereby stacks of molecules stretch across the membrane to form a hydrophilic tunnel. Structural evidence is available for both hypotheses. Thus nonactin, a macrotetralide antibiotic with highly specific transport properties for $\mathrm{K}^{+}$ions, forms a spherical potassium complex with a lipophilic exterior and an unhydrated $\mathrm{K}^{+}$ion surrounded by carbonyl oxygen atoms at the centre (Kilbourn et al. 1967). Such a structure would appear to favour a "carrier mechanism'. In contrast, crystals of free nonactin are built from plate-like molecules, associated in closely packed columns, suggesting a tunnel mechanism (Kilbourn et al. 1967). However, recent reports strongly suggest that a carrier mechanism is operative (Tosteson, 1968; Wipf et al. 1969). Crystals of the potassium complex of enniatin B contain analogous stacks of disc-shaped molecules with lipophilic exteriors (Dobler et al. 1969). However, for the gramicidins, X-ray studies (Hodgkin \& Oughton, 1957) and various physical methods (Schwyzer, 1958; Stern, Gibbons \& Craig, 1968; Ohnishi \& Urry, 1969) favour a rigid planar conformation with both a hydrophilic surface and a hydrophobic surface. Studies of the conformation of valinomycin in solution (Ohnishi \& Urry, 1969; Ivanov et al. 1969), and recent X-ray results (Pinkerton, Steinrauf \& Dawkins, 1969), suggest that the ester carbonyl groups become arranged hexagonally around the internal $\mathrm{K}^{+}$ion, as with nonactin, and other evidence favours a 'carrier mechanism' for valinomycin (Haynes, Kowalsky \& Pressman, 1969; Pinkerton et al. 1969). Members of the nigericin group can reverse the effects of valinomycin (Graven, Estrada \& Lardy, 1965). They contain a carboxyl group that must be deprotonated for complex-formation (Pressman, Harris, Jagger \& Johnson, 1967). In the crystals of monensin (Agtarap, Chamberlin, Pinkerton \& Steinrauf, 1967) the linear chain is wrapped around the complex ion, and a water molecule bridges the carboxyl group at one end to the hydroxyl groups at the other. The alkali-metal complex is bound through induced ion-dipole interactions with the oxygen atoms, analogous to the binding in valinomycin.

From such a survey of analogous compounds it appears that alamethicin falls into a class of its own. It is a pure peptide with a single carboxyl group. However, unlike the charged nigericins it forms lipid-soluble alkali-metal complexes over a wide $\mathrm{pH}$ range, which can be either neutral or positively charged (Pressman, 1968). Its unique property of voltage-dependent cationic conductance is probably a function of the charged group (Mueller \& Rudin, 1968a), for the neutral enniatins and valinomycin can develop large conductances but produce no gating effects. Unlike the valinomycin and nigericin groups, alamethicin shows poor discrimination between the alkali metals (Mueller \& Rudin, 1968a; Pressman, 1968), a result that might be expected if they all form analogous structures, for the large ring of alamethicin should be sufficiently flexible to adopt a variety of ionselective conformations. However, it appears that the two groups function quite distinctly and therefore may be structurally distinct also. Thus the valinomycin group appear to function through a univalent carrier mechanism (Tosteson, 1968; Wipf et al. 1969; Haynes et al. 1969), whereas Mueller \& Rudin $(1968 a, b)$ have shown that alamethicin demonstrates nonlinear co-operative behaviour and suggest that six (or more) alamethicin molecules are involved in the process of ion transport, clearly suggesting a pore mechanism rather than a univalent carrier process. Further, because the unique properties of alamethicin are not dependent on the nature of the lipids in the bilayer, it would seem likely that alamethicin itself would form such a pore, rather than producing channel domains in the associated lipids through which cationic transfer occurs.

We have therefore built a space filling (CoreyPauling-Koltun) model of alamethicin (Plate 1) with hydrophobic side chains placed outwards, while carbonyl groups were directed inwards. In a stacked arrangement such molecules would give a lipid-soluble tube with a hydrophilic core. On inspection of such a model one is impressed by the flexibility of glutamine-18 compared with the considerable steric constraints imposed on the peptide chain by the seven $\alpha$-aminoisobutyric acid and two proline residues. It readily bridges the ring, and both its $\alpha$-carboxyl and $\gamma$-amide groups can readily align with the amide group of glutamine-6 to provide a plausible chelating site. Such chelate formation would effectively block the centre of the ring. However, the flexibility would also let 
glutamine-18 act as a flexible arm, allowing intermolecular cationic transfer in a sort of 'bucketchain' or 'conveyor-belt' mechanism along a hydrophilic tunnel across the membrane. The free carboxyl group at one end of the chain could then protrude into one surface of the membrane or the other according to the potential gradient. By the use of natural membranes some evidence has been obtained for such cation permeation via negatively charged pores (Wallach \& Zahler, 1966; Eisenman, 1968; Shean \& Sollner, 1966).

Unfortunately, the degree of steric constraint imposed by the primary structure is not sufficient to force us to choose this model in preference to others. On the other hand, it is possible that this inherent flexibility of a ring the size of alamethicin might be intrinsic to its possible function in a channel mechanism, that might well require cooperative interactions between stacked molecules (Podleski \& Changeux, 1969). The observation that alamethicin aggregates spontaneously in solution in the protonated form, but is monomerized at high $\mathrm{pH}$, may allow further physicochemical studies (Chapman et al. 1969). We hope that this determination of the primary structure will encourage the necessary investigations of the crystal structure, and that together these may lead to a better understanding of the unique behaviour of alamethicin and of the nature of biological transport systems in general.

We are indebted to Dr A. I. McMullen (Porton) for bringing the subject of alamethicin to our attention, and for convincing us of the need for the present sequence studies. We are also grateful to him for the sample of alamethicin, for the titration results and for many helpful discussions. We thank Mr J. Slade for assistance with the amide analyses, Mr J. R. Hunter for the photography and Dr J. Thomas for a sample of diborane.

\section{REFERENCES}

Agtarap, A., Chamberlin, J. W., Pinkerton, M. \& Steinrauf, I. (1967). J. Am. chem. Soc. 89, 5737.

Atassi, M. Z. \& Rosenthal, A. F. (1969). Biochem.J. 111, 593.

Bergman, M., Zervas, L., Fruton, J. S., Schneider, F. \& Schleich, H. (1935). J. biol. Chem. 109, 325.

Blow, D. (1969). Biochem. J. 112, 261.

Bodanszky, M. \& Perlman, D. (1969). Science, N.Y., 163, 352.

Chapman, D., Cherry, R. J., Finer, E. G., Hauser, H., Phillips, M. C., Shipley, G. G. \& McMullen, A. I. (1969). Nature, Lond., 224, 692.

Chibnall, A. C. \& Rees, M. W. (1958). Biochem.J. 68, 105.

Dobler, M., Dunitz, J. D. \& Krajewski, J. (1969). J. molec. Biol. 42, 603 .

Eisenman, G. (1968). Fedn Proc. Fedn Am. Socs exp. Biol. 27, 1249.

Graven, S. N., Estrada, O. S. \& Lardy, H. A. (1965). Proc. natn. Acad. Sci. U.S.A. 53, 1076.
Gray, W. R. (1967a). In Methods in Enzymology, vol. 11, p. 139. Ed. by Colowick, S. P. \& Kaplan, N. O. New York: Academic Press Inc.

Gray, W. R. (1967b). In Methods in Enzymology, vol. 11, p. 469. Ed. by Colowick, S. P. \& Kaplan, N. O. New York: Academic Press Inc.

Gray, W. R. \& Hartley, B. S. (1963). Biochem. J. 89, 59 .

Haynes, D. H., Kowalsky, A. \& Pressman, B. C. (1969). J. biol. Chem. 244, 502.

Heilmann, J., Barrolier, J. \& Watzke, E. (1957). HoppeSeyler's Z. physiol. Chem. 309, 219.

Hodgkin, D. C. \& Oughton, B. M. (1957). Biochem. J. $65,752$.

Ivanov, V. T., Laine, I. A., Abdulaev, N. D., Senyavina, L. B., Popov, E. M., Ovchinnikov, Yu. A. \& Shemyakin, M. M. (1969). Biochem. biophys. Res. Commun. 34, 803.

Kilbourn, B. T., Dunitz, J. D., Pioda, L. A. R. \& Simon, W. (1967). J. molec. Biol. 30, 559.

King, E. J. (1951). Micro Analysis in Medical Biochemistry, 2nd. Ed., p. 10. London: J. and A. Churchill Ltd.

Matsubara, H., Singer, A. \& Sasaki, R. M. (1969). Biochem. biophys. Res. Commun. 34, 719.

Meyer, C. E. \& Reusser, F. (1967). Experientia, 23, 85.

Mueller, P. \& Rudin, D. O. (1968a). Nature, Lond., 217, 713.

Mueller, P. \& Rudin, D. O. (1968b). J. theoret. Biol. 18, 222.

Offord, R. E. (1966). Nature, Lond., 211, 591.

Ohnishi, M. \& Urry, D. W. (1969). Biochem. biophys. Res. Commun. 36, 194.

Pinkerton, M., Steinrauf, L. K. \& Dawkins, P. (1969). Biochem. biophys. Res. Commun. 35, 512.

Podleski, T. \& Changeux, J. P. (1969). Nature, Lond., 221, 541.

Pressman, B. C. (1968). Fedn Proc. Fedn Am. Socs exp. Biol. 27, 1283.

Pressman, B. C., Harris, E. J., Jagger, W. S. \& Johnson, J. H. (1967). Proc. natn. Acad. Sci. U.S.A. 58, 1949.

Rees, M. W. (1958). Biochem.J. 68, 118.

Reusser, F. (1967). J. biol. Chem. 242, 243.

Schecter, I. \& Berger, A. (1966). Biochemistry, Easton, 5, 3371.

Schwyzer, R. (1958). Chimia, 12, 53.

Shean, G. M. \& Sollner, K. (1966). Ann. N.Y. Acad. Sci. 137, 759.

Shotton, D. M. \& Hartley, B. S. (1970). Nature, Lond., 225, 802.

Smith, I. (1953). Nature, Lond., 171, 43.

Spackman, D. H. (1963). Fedn Proc. Fedn Am. Socs exp. Biol. 22, 244.

Stern, A., Gibbons, W. \& Craig, L. C. (1968). Proc. natn. Acad. Sci. U.S.A. 61, 734.

Tang, J. \& Hartley, B. S. (1970). Biochem. J. (in the Press).

Tosteson, D. C. (1968). Fedn Proc. Fedn Am. Socs exp. Biol. 27, 1269.

Wallach, D. F. H. \& Zahler, H. P. (1966). Proc. natn. Acad.Sci. U.S.A. 56, 1552.

Wipf, H. K., Pache, W., Jordan, P., Zahner, H., KellerSchierlein, W. \& Simon, W. (1969). Biochem. biophys. Res. Commun. 36, 387. 